\title{
Emotion, deliberation, and the skill model of virtuous agency
}

\author{
Charlie Kurth
}

Department of Philosophy, Washington University in St. Louis, St. Louis, Missouri

\section{Correspondence}

Charlie Kurth, Department of Philosophy, Washington University in St. Louis, One Brookings Drive - CB 1073, St. Louis, MO 63130.

Email: ckurth@wustl.edu

\begin{abstract}
A recent skeptical challenge denies deliberation is essential to virtuous agency: what looks like genuine deliberation is just a post hoc rationalization of a decision already made by automatic mechanisms. Julia Annas's account of virtue seems well-equipped to respond: by modeling virtue on skills, she can agree that virtuous actions are deliberation-free while insisting that their development requires significant thought. But Annas's proposal is flawed: it over-intellectualizes deliberation's developmental role and under-intellectualizes its significance once virtue is acquired. Doing better requires paying attention to a distinctive form of anxiety-one that functions to engage deliberation in the face of decisions that automatic mechanisms alone cannot resolve.
\end{abstract}

\section{KEYWORDS}

agency, anxiety, deliberation, emotion, metacognition, virtue

\section{1 | INTRODUCTION}

What role should deliberation play in our understanding of virtuous agency? A common thought maintains that it is essential. It is essential both to our ability to appropriately work through inconsistencies in our moral beliefs and judgments, and to our ability to understand, and so navigate, the complexities of moral life. Granted, there is disagreement about how exactly to understand deliberation's role in all this - the basic picture, however, is widely endorsed. ${ }^{1}$ But is this position tenable? Even a little reflection reveals that many virtuous acts proceed without deliberation. Recent work in moral psychology brings further trouble. Drawing on empirical research, this work suggests emotions and other automatic mechanisms-not deliberation-drive practical decision making: what

\footnotetext{
${ }^{1}$ For a representative sample, see Brink and Nelkin (2013), Korsgaard (2009), Kennett and Fine (2009), Wolf (1990), Watson (1982), and Frankfurt (1971).
} 
seems like genuine deliberation is really just post hoc rationalization (Doris, 2015; Haidt, 2001). If these skeptical worries are correct, then there is little-if any-role for deliberation in thought and action, much less virtuous thought and action.

Against this backdrop, the skill model of virtuous agency has much appeal. ${ }^{2}$ This model takes the fluid performances of artisans, athletes, and musicians as the paradigm of excellence in human agency. It then notes that though these individuals perform automatically, without contemplation or reflection, they can do so only because of the conscious thought they have put into learning their skills. Thus, the skill model suggests we can vindicate deliberation while also accommodating the empirical work that underlies the skeptic's claims about the automatic nature of virtuous agency.

But while tempting, the skill model cannot substantiate our commonsense thoughts about the importance of deliberation for virtue. To show this, I focus on Julia Annas's recent proposal. As we will see, her version of the skill model seems particularly well-equipped to address skeptical worries about deliberation's significance. But, as we will also see, the progress her proposal makes comes at the cost of an implausible account of the psychology of the virtuous agent-one that overstates deliberation's role for the development of virtue and understates its contribution once virtue has been acquired. ${ }^{3}$ While recognizing the limitations of Annas's proposal is important on its own, this critical investigation has larger significance: it enriches our understanding of the moral psychology of virtuous agents. More specifically, we will see that developing a better response to the skeptic requires giving greater attention to emotion and, in particular, to a distinctive form of anxiety. Recognizing this not only helps us better understand deliberation's central role, but also reveals where the skeptic goes wrong. In short, deliberation is essential to our ability to work through difficult decisions. But we can engage in it only because of emotions like anxiety that function to both signal that we face a difficult choice - a choice that automatic mechanisms alone cannot address - and initiate the reasoning that helps bring good practical judgment. The result is a more compelling skill-based account of deliberation's place in virtuous thought and action.

\section{2 | THE CHALLENGE}

While the claim that deliberation is essential to virtue can be fleshed out in many ways, the most plausible versions have two features: they tie virtuous agency not to actual conscious deliberation, but to the capacity for it, and they aim to provide accounts of what virtuous decision making amounts to for ordinary humans, not perfect or ideal agents. ${ }^{4}$ Much of the appeal of this "deliberationist" position lies in the thought that deliberative capacities-what underlies things like inquiry, reflection, reasoning, and reassessment-are essential not just to human agency in general, but also to the exemplification of virtuous thought and action. ${ }^{5}$ Intuitively, it is (in part) because normal adults can consciously assess, revise, and act for reasons that we view them as agents. Moreover, we take our development as agents-our ability to become virtuous - to go hand in hand with the

\footnotetext{
${ }^{2}$ While the skill model is often defended by those working in the Aristotelian tradition (e.g., Annas, 2011; Bloomfield, 2000; Dreyfus \& Dreyfus, 1991; Foot, 1978; Stichter, 2015), it also has broader appeal (e.g., Kennett \& Fine, 2009; Railton, 2009).

3 As will become clearer below, while some of the concerns that I raise about Annas's account have been noted by others, the critical portion of my argument is novel in situating her view (and the associated criticisms) within the context of recent empirically motivated skepticism about deliberation.

4 Accounts of ideal agency can be found in (e.g. Rawls (1971, pp. 416-424) and McDowell (1998). But they have familiar problems. For instance, given the high degree of idealization these proposals involve, how can agents of this sort serve as normative standards for ordinary human agents (e.g., Doris, 2015; Enoch, 2006)?

5 In what follows, I will be using "deliberation" and "epistemic behaviors" to refer to this broad suite of capacities, not just (conscious) reasoning.
} 
development of our deliberative capacities. Similarly, for our responsibility intuitions: it is (partly) because of our capacity for deliberation-our ability to recognize and work through deficiencies in our beliefs and goals - that we take ourselves to be subject to praise, blame, and an expectation to become better. So, for instance, David Brink and Dana Nelkin maintain that

[o]ur paradigms of responsible agents are normal mature adults with certain sorts of capacities. We do not treat brutes or small children as responsible agents. Brutes and small children both act intentionally, but they act on their strongest desires or, if they exercise deliberation and impulse control, it is primarily instrumental reasoning in the service of fixed aims. By contrast, we suppose, responsible agents must be normatively competent. They must not simply act on their strongest desires, but be capable of stepping back from their desires, evaluating them, and acting for good reasons. This requires responsible agents to be able to recognize and respond to reasons for action (Brink \& Nelkin, 2013, p. 292). ${ }^{6}$

Thus, making sense of what it is to be a virtuous agent seems to require vindicating the importance of deliberation for human thinking and doing. ${ }^{7}$

The significance of this vindicatory project is further highlighted by two empirically motivated lines of skepticism that emerge from recent work by Jonathan Haidt (2001) and John Doris (2015). ${ }^{8}$ First, research on dual-process theories of mind suggests practical judgment starts from, and is largely driven by, automatic_-not conscious_-mental processes. More specifically, the skeptic starts by drawing on work indicating that there are two general types of mental processing: Type 1 processes that are inter alia quick, effortless, unconscious, and (often) affectively valenced; Type 2 processes that are inter alia slow, effortful, conscious, and (largely) affectively neutral. He then points to research suggesting that framing effects and seemingly irrelevant situational features can bring significant changes in one's subsequent practical judgments (e.g., foul odors bring harsher judgments of responsibility; circling "we" rather than "I" in a passage gets people to avow more communitarian values). But if trivial situational features like these can have such significant effects on our practical judgments, then it is hard to see how deliberation could be playing much of a role. A better explanation, says the skeptic, is that practical judgment is the product of Type 1 processes.

The second worry comes from work on confabulation. This research indicates that we are generally unaware of the causes of our behavior-be it picking up a certain object or making a particular practical judgment. But our lack of awareness does not stop us from confidently offering (typically false) explanations for why we did what we did. The skeptic takes these findings to undermine the thought that our reason-giving behavior amounts to genuine deliberation: given our tendency to confabulate, for all we know, our "deliberation" is nothing more than a post hoc rationalization of a judgment we have already made.

The overall picture of agency suggested by this work is quite disconcerting. These skeptical worries, if well-founded, reveal that deliberation does not-perhaps cannot—play the role in decision making and agency proposed by deliberationists. Importantly, the skeptic need not claim that we never engage in genuine deliberation. Rather, he need only maintain that the deliberation we

\footnotetext{
${ }^{6}$ For similar claims, see the references in note 1.

${ }^{7}$ Some will resist the claim that deliberation is essential on the grounds that nondeliberative agency displays all the intelligence and reasons-responsiveness that we need in order to account for virtue and its development (e.g., Stanley, 2011 and, perhaps, Railton, 2014). However, while proposals like this point to middle-ground between Haidt/Doris-style skepticism and a vindication of deliberation, they nonetheless come at a cost to the commonsense thoughts about deliberation's role noted in the text. Thus, before going this route, we should investigate the prospects for a vindication of deliberation's role.

${ }^{8}$ Because I take these skeptical worries to be familiar, my discussion will be brief.
} 
engage in fails to plays an interesting - much less essential—role in shaping virtuous thought and action (e.g., Doris, 2015, pp. 22-23). But if that is correct, if there is no interesting or essential role for deliberation, then much of what we take to be distinctive about humans as rational and moral agents is threatened: our intuitions to the contrary, deliberative capacities are irrelevant for things like identifying normal adults (but not children or brutes) as agents, understanding what is involved in becoming virtuous, and making sense of responsibility. Such revision to ordinary thought is quite radical. As Jeanette Kennett and Cordelia Fine observe:

If it should turn out that human agency is of the minimal kind suggested by [the skeptic,] then our moral concepts will lack application, and moral discourse and practice will be systematically in error since they are irreducibly predicated on the assumption that we are reason responders [i.e., creatures have the capacity to respond to reasons as reasons and to guide their behavior accordingly] (Kennett \& Fine, 2009, p. 85, emphasis added; also Tiberius, 2013, p. 223; Sauer, 2011).

In light of all this, one should feel the force of the skeptic's challenge: Can there be a substantive place for deliberation given the empirical arguments that undergird the skeptic's objections? More specifically, if the deliberationist is to vindicate our pre-theoretical beliefs about the importance of deliberation for virtuous agency, she must (i) establish that deliberation plays a substantive and essential role in good practical decision making and agency, while (ii) granting that practical judgment is a process that starts from, and is largely driven by, automatic processes. ${ }^{9}$ In what follows, I take up this challenge.

\section{3 | THE SKILL MODEL OF VIRTUOUS AGENCY}

As we noted, in the face of the above skeptical challenge, skill-based models of virtuous agency have much appeal. These proposals take the fluid performances of accomplished athletes, musicians, and craftspersons as the paradigm of human excellence and use them as a model for understanding virtuous agency more generally. This move is significant. If we can understand virtuous thought and action as akin to skilled performances, then we have a model of agency that can secure an essential, but limited, role for deliberation in our understanding of virtue. After all, musical and athletic skills require conscious effort to acquire; but once one has become proficient, one can perform automatically, without conscious thought or reflection. Thus, the focus on skills gives us a proposal that is both applicable to ordinary humans and well-equipped to answer the challenge that proponents of deliberation face.

To give this claim substance, I focus on Julia Annas's recent proposal. There are several reasons for this. Not only is Annas explicit about wanting to secure an essential place for deliberation in virtuous agency (2011, chap. 1), but she also wants her account of virtue to be something ordinary human agents can attain (pp. 30-32). ${ }^{10}$ Moreover, and as we will see, in comparison with other versions of the skill model, Annas's account emphasizes features of virtue and its development that make for a particularly forceful reply to the skeptic.

\footnotetext{
9 One might reasonably hold that responding to the skeptics need not involve granting (all) the data on which their arguments rest (e.g., Jacobson, 2012; Pizarro \& Bloom, 2003). While I am sympathetic to this move, it is worth seeing if the skeptics' conclusions can be resisted even if we grant them their starting place.

${ }^{10}$ While Annas is primarily concerned to give an account of virtue applicable to ordinary humans, she acknowledges that there is a notion of virtue as a regulative ideal-though ordinary humans can never secure this "full" virtue, it is something they can "aspire" to (pp. 64-65). Following Annas, my focus will be on the primary, nonidealized notion of virtue.
} 
Turning to details, according to Annas, there is a strong analogy between the development and exemplification of skills and the development and exemplification of virtues:

the kind of practical reasoning found in the development and exercise of virtue is like the kind of reasoning that we find in the development and exercise of practical expertise. ... [V]irtue is habituated, built up over time and from experience by a process of learning.... The virtuous person acts by way of immediate response to situations, but in a way that exhibits the practical intelligence of the skilled craftsperson or athlete (Annas, 2011, p. 169).

As this quote suggests, Annas's proposal has two elements. First, like a skill, virtuous agency is learned. In particular, to count as the form of learning necessary for the acquisition of skills and virtues, one's development must be something that meets two conditions: its development that (i) proceeds via explicit instruction whereby one comes to recognize the reasons for doing one thing rather than another, and that (ii) involves one exhibiting a drive to aspire. As she explains, this "drive" consists in the combination of three inter-related motivations: a desire to understand why the teacher does what she does, a desire to be able to execute the skill in a self-directed way (rather than exhibiting a mere mimicking capacity), and a desire to improve (pp. 17-18).

Second, and again like a skill, once the underlying capacities have been acquired, the subsequent exemplification of virtue is automatic, but intelligent; virtuous thought and action is akin to the "flow" experiences that Mihalyi Csikszentmihalyi (1991) has used to characterize optimal human performance. Such performances are paradigmatic examples of practical intelligence: they are cases where one demonstrates the reasons responsiveness that is characteristic of virtuous agency, but does so without consciously deliberating. As Annas explains, '[h]onest actions will be experienced by the mature honest person in the "flow" way; however complex and hard to navigate the circumstances are, there is no felt resistance to acting honestly' (p. 75). The agency of both the skilled and the virtuous is 'unmediated by deliberation' and 'unimpeded by frustration and inner conflict' (pp. 71-73).

To see how Annas's proposal helps address our challenge, first consider her account of learning and development. Unlike versions of the skill model that take learning to typically involve explicit instruction that appeals to reasons (e.g., Dreyfus \& Dreyfus, 1991; Stichter, 2015), Annas's account requires it. As such, she can specify an essential role for deliberation. Moreover, because Annas takes virtuous agency to be on par with the flow experiences of athletes and artisans, she can capture the data underlying the empirically motivated skepticism. After all, since the exemplification of virtue once acquired is a flow experience, it is action that is both automatic and intelligent. So she can maintain that virtuous agency is driven by automatic processes, while still insisting that it is not just mindless habit. Finally, because developing one's agential capacities is, like becoming a skilled musician, a process that requires developing understanding via explanations that appeal to underlying reasons, one will be able to accurately explain why one did what one did (p. 20). Because other versions of the skill model avoid tying virtuous action to the ability to provide such explanations (e.g., Bloomfield, 2000; Dreyfus \& Dreyfus, 1991), we again see an advantage in Annas's proposal: given her explanation requirement, she seems particularly well-placed to respond to the skeptic's charge that what appears to be "reasoning" is nothing but post hoc rationalizations. ${ }^{11}$

\footnotetext{
${ }^{11}$ To be clear, my claim is that Annas's proposal appears better equipped to answer the skeptic's challenge. Other skill-based accounts might be more plausible all things considered—a possibility I take up in $§ 7$.
} 


\section{I TWIN PROBLEMS WITH ANNAS'S PROPOSAL}

With this understanding of Annas's skill model in hand, I will argue that her proposal offers an account of the moral psychology of the virtuous agent that is over intellectualized in its picture of how virtue is acquired, but under intellectualized in its explanation of the role for deliberation once virtue has been acquired. But since Annas's version of the skill model seems to be the one that's best equipped to answer the skeptic, the result will be real cause for concern regarding the ability of the skill model to provide a response to the challenge from $\S 2$. The balance of the paper develops a better way forward.

Problem 1: Over Intellectualized. Annas takes skill and, by analogy, virtue acquisition to require learning that involves both (a) explicit instruction that appeals to reasons and (b) a drive to aspire. As we saw, it is this intellectualized account of learning that secures an essential role for conscious deliberation in virtuous thought and action. Thus, her proposal would be in trouble if it were possible for individuals to develop sophisticated skills without either (a) or (b). On this front, things like language acquisition seem problematic: while learning a language might be facilitated by explicit instruction and a drive to aspire, neither appears to be necessary as evidenced by emersion methods. Moreover, even if we grant that language learning requires instruction (Annas, 2008, p. 23), why think it must be the highly intellectualized learning Annas's account demands-namely, instruction that highlights the underlying reasons for (say) using one verb-form rather than another? ${ }^{12}$ Similarly, consider the culinary arts. One can become a skilled cook even if one's talent results, not from explicit instruction that appeals to reasons, but rather from a combination of mimicking others (e.g., recipes, cooking shows) and one's own trial-and-error efforts.

In response, Annas might maintain that the kind of learning relevant to the development of skilled and virtuous agency is learning that brings a true appreciation of the underlying reasons-it is learning that allows the individual to explain why she did what she did. Without this ability to explain, we have a mere "knack," not genuine practical expertise (2011, pp. 19-20; Annas, 2008). But this move comes at a big cost. Granted, by requiring the rich understanding that would allow one to explain why one acted as one did, Annas can rule out skills acquired from trial-and-error or emersion as counterexamples. However, this explanatory requirement also appears to rule out the artisans, athletes, and musicians that she points to as paradigmatic instances of individuals who have acquired their expertise in the right way: as accomplished as they are, they are often unable to provide explanations for what they have done. ${ }^{13}$ In short, in going this way, Annas ends up undermining her ability to use these skilled experts as a model for virtue. ${ }^{14}$

\footnotetext{
12 Consider that novelists like Mark Twain and William Faulkner dropped out of school at (respectively) age 12 and 14 . They seem to be living examples of literary exemplars despite (presumably) lacking either the explicit instruction or drive for understanding that Annas takes as essential.

${ }^{13}$ Brownstein (2014) develops an argument of this sort against Annas. One of his examples is the following quote from the Hall of Fame running back Walter Payton: "people ask me about this move or that move, but I don't know why I did something. I just did it." Also see Bloomfield (2000), and Dreyfus and Dreyfus (1991).

14 At this point, Annas might try to draw on empirical work suggesting that skilled athletes can explain their actions (e.g., Christensen, Bicknell, McIlwain, \& Sutton, 2015, regarding expert mountain bikers; Sutton, 2007, on professional cricket batters). But there is reason to be concerned about the effectiveness of this move. First, showing that some skilled athletes can articulate their reasons does not mean all can-witness Walter Payton. So, unless more can be said, the objection in the text stands. Second, it is unclear whether this empirical research even does the work Annas needs it to do. More specifically, the research supports the claim that (some) skilled athletes display a distinctive capacity for higher-order, top-down cognitive control. So it provides evidence that these individuals rely on Type 2 processing. But since not all Type 2 processing is conscious (e.g., Price \& Norman, 2008), it is unclear whether we get evidence for the further claim that Annas needs-namely, that skilled athletes can articulate their reasons for doing what they did.
} 
Stepping back, we get a more general lesson. If the practical expertise of these paradigms of human excellence fail Annas's explanation requirement for learning, then why think skill or virtue acquisition must be so intellectualized? It appears that while Annas may be right that skills (and so virtues) are acquired more efficiently when they come via explicit instruction and a drive to aspire, she errs in thinking these features are essential to the learning process. If we are to vindicate deliberation, we need to look elsewhere.

Problem 2: Under Intellectualized. As we noted, Annas takes the harmonious, automatic performances of athletes and craftspersons as evidence that virtuous thought and action will be similarly free of unease, struggle, and deliberation. Moreover, this strong analogy with flow experiences provides a forceful reply to the skeptic: if virtuous action is both automatic and intelligent, then there is no need to give - or substantiate - a role for deliberation once virtue has been acquired. But Annas recognizes that this psychological picture may seem dubious in light of our personal experiences with difficult (moral) choices and so she identifies two ways that unease, struggle, and deliberation can be consistent with virtuous agency.

First, there are cases where the virtuous agent struggles and feels uneasy because she's faced with challenges she cannot control: she, say, gives generously but feels regret and discomfort because she cannot do more - there are just too many who need help. Such unease is consistent with virtue because it results from difficult external circumstances, rather than an internal conflict in desires and values (e.g., she gives but regrets her self-interested resistance to giving more) (p. 78). Second, there are cases where the virtuous agent must think through a complicated situation. Deliberation in these cases is consistent with virtuous agency because the 'activity is harmonious in the sense that there is no disruption of intent' (p. 77); like a skilled surgeon who comes across an unexpected complication, one's reflection proceeds 'easily and without internal struggle' (Annas, 2008, pp. 32-33).

However, while Annas is right that an account of virtue applicable to ordinary human agents needs to make room for cases like these, virtuous human agents do-and should — feel uneasy and deliberate more often than Annas's account allows. To better draw this out, consider the following:

Refugees. You provide assistance to a group of refugees and do so from sympathy. But your decision is a source of unease, not because you feel regret, but rather because your decision to give so much strains your other goals and values (e.g., regarding your family) - it gets you thinking about whether you are making the correct choice.

Intuitively, this is an instance of virtuous action, not merely an action that brings morally correct results. You do not just provide assistance from sympathy for the refugees but-through your unease-you evince a broader emotional attunement. Moreover, the anxiety you feel about your decision, and the deliberation this provokes, reflects an admirable form of concern: a sensitivity that manifests your appreciation of the significance and complexity of the decision you are making.

But notice: the refugee case provides an instance of virtue that is at odds with the psychological picture Annas presents. In particular, we have virtuous agency that involves both internal struggle and disruptive deliberation: not only are you concerned about whether your sizable contribution will put too much strain on your other commitments, but this concern interrupts your decision makingit gets you to pause and assess things more closely. Moreover, and in a more normative vein, the case reveals the value we place in someone who, at times, not only feels uneasy or anxious in the face of difficult and novel decisions, but who-as a result of this unease-stops to reassess the 
situation at hand. ${ }^{15}$ To be clear, I do not deny that the unease- and deliberation-free agency of the above surgeon example is admirable; my point is that such cases do not exhaust our understanding of virtuous agency. As the refugee example reveals, the virtuous agent is someone who feels unease about how to act and who reassesses her plans as her situation becomes less familiar. An individual who finds herself in a novel or difficult situation like this-but who isn't worried and doesn't reassess-strikes us as flawed or deficient in an important way: like someone devoid of anger (and the associated drives) in the face of a heinous crime.

Annas might respond that this case only reveals the rather obvious fact that some individuals are more virtuous than others: while it might make sense for an internally conflicted individual to feel uncertain and deliberate, a more virtuous person would not be conflicted-though problems may arise that require reflection, the virtuous individual will proceed fluidly and without disruption (p. 77). ${ }^{16}$ However, so long as we are focusing on a notion of virtuous agency applicable to ordinary-not ideal-agents, it is hard to see how this move helps. After all, for any level of actual human development, there will be situations where even the most experienced individuals face novel situations-situations quite unlike what they have seen before. When this happens, past experience cannot guide automatic action. Thus, one must have the ability to recognize that one faces a novel situation in a way that prompts one to pause and consider whether one's initial inclination about what to do is correct. What makes the unease of someone in the refugee case admirable is that such a person evinces this attunement-her worry signals a novel or difficult situation and prompts reassessment.

Moreover, the claim that skilled/virtuous action involves a tendency to feel uneasy and reassess in the face of uncertainty is supported by empirical research on the decision-making of experienced firefighters (Klein, 1999). For these individuals, initial decisions about how to fight a fire come automatically based on intuitive assessments grounded in past experience. But unnoticed features or changing conditions can reveal problems in the initial plan. These anomalies can in turn spark 'discomfit' that signals trouble and motivates reflection, reassessment, and changes in plans (p. 33). So while Annas is right that the expert is attuned to 'what is happening and respond[s] appropriately to feedback' (p. 77), she is mistaken in thinking that this process is always harmonious, easy, or free of disruption. In fact, the firefighter research suggests unease, disruption, and reassessment will sometimes be exactly what is needed.

The Upshot. One might think the above difficulties would be avoided by versions of the skill model that are both less intellectualized in their account of learning and less restrictive regarding the role of deliberation once skill/virtue has been acquired. Though we will return to this possibility in $\S 7$, we have already seen that these alternative proposals lack the resources needed to respond to the skeptic (§3). But there is more to our critical investigation than just these negative conclusions: we have also gained new insights into the moral psychology of the virtuous. The refugee case and the firefighter research suggest that virtuous thought and action involves both a tendency to feel uneasy about how to act as one's situation grows increasingly unfamiliar, and a tendency for that unease to prompt a reassessment of one's initial intentions. I take this, in turn, to motivate the idea that a distinctive variety of anxiety-anxiety about practical decisions-is central to a plausible account of the psychology that undergirds virtuous agency: it is an emotion that gets us deliberating about novel and difficult situations-situations where automatic processes alone are unable to provide

\footnotetext{
15 This point has been recognized by others: Arpaly and Schroeder (2014, pp. 241-245), Slote (2014, pp. 175-176), and Stohr (2003). I say more about this in Kurth (2018a).

${ }^{16}$ Foot (1978) also makes a move of this sort.
} 
guidance about what to do. In what follows, I sketch a picture of this practical anxiety and show how it allows us to answer our challenge.

\section{5 | PRACTICAL ANXIETY: WHAT IT IS AND WHAT IT DOES}

\section{1 | A primer on anxiety}

To understand what practical anxiety is and how it can help vindicate deliberation, we need some background. Anxiety, as a general psychological phenomenon, is an emotional response to uncertainty about possible threats or challenges. ${ }^{17}$ Fleshing this out, we can see anxiety as an emotion that integrates two capacities that are concerned with problematic levels of uncertainty. First, on the input side, anxiety brings an important form of awareness: it functions as an alarm or signal that automatically identifies, and directs our attention toward, potential threats. As the psychologist Andrew Mathews explains, anxiety brings 'an automatic processing bias, initiated prior to awareness, but serving to attract attention to environmental threat cues, and thus facilitating the acquisition of threatening information' (Mathews, 1990, p. 461). Second, on the output side, anxiety motivates a set of situation-specific risk minimization efforts and epistemic behaviors: anxiety's detection of a potential threat prompts a combination of (potentially conscious) information gathering, situational assessment, and higher cognitive processing (e.g., memory recruitment, reasoning, re-assessment) that is aimed at helping us address the uncertain threat that we face. Christopher Hookway nicely brings these points together:

By making me sensitive to risks and dangers, unreflectively alert to possible hazards, anxiety may enable me to act spontaneously and effectively and prevent me [from] carelessly exposing myself to unnecessary risks. The emotional state provides a tool for collecting relevant information and planning actions in light of it... (Hookway, 1998, pp. 218-219). ${ }^{18}$

These initial observations allow us to draw out two further aspects of anxiety that will be important for the discussion that follows. First, while we often talk of conscious experiences of anxiety, the above indicates that it can also operate below the level of conscious awareness. More specifically, since anxiety is a mechanism that combines a sensitivity and responsiveness to potential threats and challenges, it is likely to manifest consciously only when some threshold of problematic uncertainty has been met. Put another way, felt anxiety is an alarm that is triggered by instances of particularly problematic uncertainty and that marks the associated ramping up of cognitive resources to address it (Corr, 2008; Kurth, 2018b). ${ }^{19}$

\footnotetext{
${ }^{17}$ For a more detailed discussion of anxiety's function and underlying cognitive architecture, see Kurth (2016, 2018b, chaps. 2-3), Davis, Walker, Miles, and Grillon (2010), Öhman (2008), Corr (2008), Barlow (2001), Gray and McNaughton (2000), and Marks and Nesse (1994).

${ }^{18}$ To be clear, in claiming that anxiety can be beneficial, I do not deny it can lead to problems. Intense bouts (or deficits) of anxiety can be disastrous. Rather, my aim is to draw out that even though anxiety can sometimes go awry, it-like other dimensions of our emotional repertoire - often manifests in a moderate and beneficial manner: a twinge of concern about the situation at hand, not a consuming worry about what might happen. In this way, anxiety is no different than, say, fear, anger, or joy: these emotions are good things to have even though they can manifest in unfortunate ways (e.g., phobias, rage, manias). I return to this in $\S 6$. It is also worth noting that this picture of anxiety as generally beneficial is widely endorsed by both social and clinical psychologists (e.g., Barlow, 2001; Leary \& Kowalski, 1995; Marks \& Nesse, 1994); it is gaining increasing attention among philosophers as well (e.g., Hookway, 1998; Kurth, 2015, 2016, 2018b; Nagel, 2010).

19 This picture of anxiety as a system that can recruit additional (cognitive, physiological) resources on an as-needed basis is thought to be a general feature of emotions, not something specific to anxiety. See, for example, Lewis (2005), Levenson (1999).
} 
Second, though anxiety brings a general sensitivity and responsiveness to uncertainty, we also find diversity in both the situations that provoke it, and the behaviors that subsequently result. For instance, work by the psychologist Norman Endler indicates that tendencies to become anxious cluster into (at least) three kinds of situations: situations where one faces the possibility of physical harm, situations where one might face social evaluation or sanction, and situations whose novelty or difficulty make one uncertain about what to do or what will happen (Endler \& Kocovski, 2001). Moreover, given the above observations about the value of anxiety, we should expect that the situational sensitivities identified by Endler will prompt corresponding behaviors that can help one address the particular kind of uncertainty at hand. And we do. Anxiety felt in physically threatening situations (e.g., being approached by a stranger in a dark parking lot) brings avoidance and escape behaviors (Perkins \& Corr, 2006). Individuals anxious about how they are being evaluated by others tend to become more deferential and are more likely to try to make amends for social errors they may have made (Leary \& Kowalski, 1995). Finally, and as we will see in greater detail below, individuals who become anxious in the face of novel or difficult challenges engage in information gathering, reassessment, and other epistemic behaviors as they try to figure out what to do (MacKuen, Wolak, Keele, \& Marcus, 2010).

Taken together, these observations suggest both that the label "anxiety" picks out a family of emotional responses that share a common core, and that these responses take on distinct forms in order to help individuals address specific kinds of problems. In particular, we see that anxiety can manifest in (at least) three distinctive ways. (1) There is a variety of "environmental" anxiety that makes us aware and avoidant of the physical dangers that surround us. (2) There is a more interpersonally oriented "social" anxiety that prompts things like deference and caution in situations where we are uncertain about how we are being evaluated by others. (3) There is a "practical" anxiety that both helps us recognize that we face a novel or difficult decision, and that prompts epistemic behaviors aimed at helping resolve our underlying uncertainty. ${ }^{20}$

\section{2 | Practical anxiety and uncertainty about what to do}

The discussion so far identifies an emotion we can plausibly call practical anxiety. To help us both further flesh out what anxiety of this sort amounts to, and demonstrate that it is a genuine psychological phenomenon, consider an example. Your mother's Alzheimer's has advanced dramatically in the last year and you can no longer provide her with the care she needs. You are inclined to follow the doctor's recommendation and put her in a nursing home. But this decision makes you anxiousIs this really the right thing to do? Given your anxiety, you start to reflect on the details of the situation you face: your mother was always so concerned about elderly care facilities. Recalling this, you now wonder: would she have thought that in a situation like this it would be inappropriate to put her in a nursing home? In exploring this question, you are trying to sort out how best to reconcile your mother's needs, fears, and desires. Still unsure, you decide to ask a close friend for guidance and are prepared to revise your thinking about what to do based on your conversation.

In this example we see that your anxiety functions as a signal-it helps you see that you face the challenge of figuring out how best to reconcile your mother's medical needs with her wish not to be put in a nursing home. But your anxiety also generates epistemic behaviors aimed at helping you do this: given your worries about what to do, you start thinking about the details of your mother's situation and

${ }^{20}$ Are environmental, social, and practical anxiety distinct (natural) kinds or do they merely represent robust cultural modifications of a more basic anxiety response? How we answer this will depend on thorny issues about, for example, the nature of (psychological) kinds and the relationship between genes and culture. Fortunately, nothing in what follows turns on these issues. I discuss these issues in Kurth $(2016,2018 b)$. 
solicit input from those you trust. Your practical anxiety, in short, integrates (i) a sensitivity to novel and difficult choices with (ii) epistemic behaviors that are driven by a concern to get things right.

While this case provides a familiar example of practical anxiety in action, it also allows us to better understand how practical anxiety relates to recent work in dual-process theories of metacognition and agency. Of particular note are the affinities that practical anxiety has with recent discussions of "epistemic" (or "metacognitive") feelings (e.g., Arango-Muñoz, 2010; Nagel, 2010; Thompson, 2009; Proust, 2009; Hookway, 1998; c.f., Oppenheimer, 2008). Epistemic feelings are mechanisms of metacognition. In the language of dual-process theory, they are Type 1-like processes that (i) monitor and assess mental states with regard to particular normative criteria (e.g., truth, accuracy, coherence) and that (ii) generate feelings of (dis)fluency to the extent that the relevant normative criteria have (not) been met. These assessments (and the associated feelings they bring) can then (iii) engage Type 2 mental processing-prompting, for instance, reflection and reassessment in response to inconsistency or insufficient coherence. So understood, practical anxiety can be seen as one of the (likely many) epistemic feelings that beings like us have. More specifically, practical anxiety is a metacognitive mechanism that (a) is triggered by an assessment that some threshold of uncertainty about what to do has been met, and that (b) tends to generate feelings of unease and associated epistemic behaviors (information gathering, reflection, reassessment) aimed at resolving the uncertainty at hand (Kurth, 2015, 2016).

Understanding anxiety as a metacognitive mechanism that brings a sensitivity and responsiveness regarding what the best course of action is also allows us to draw out an important difference between practical anxiety and the social anxiety discussed above. As we saw, social anxiety is elicited in situations where one might be evaluated by others, and tends to bring defensive and self-interested behaviors - deference, efforts to make excuses for one's faux pas, and the like. This suggests that, in contrast to the concerns for accuracy that come with practical anxiety, social anxiety brings a more ego-defensive set of motivations. So understood, social and practical anxiety are forms of anxiety that, as metacognitive feelings, function to track and respond to different normative criteria. In the case of social anxiety, the criterion concerns appropriate self-presentation and, when triggered, it brings a range of ego-defensive responses (Leary \& Kowalski, 1995). By contrast, for practical anxiety, the normative criterion concerns good decision making and, when activated, it prompts open-minded forms of inquiry and deliberation (Kurth, 2016, 2018b). Moreover, that these two varieties of anxiety engage different normative criteria and associated motivations makes sense: practical anxiety's accuracy orientation fits well with our understanding of it as a sensitivity to novel or difficult choices; social anxiety's egodefensive orientation meshes with our account of it as a sensitivity to being evaluated by others.

We get further support for our metacognitive account of practical anxiety and its accuracy orientation from research by the political scientist Michael MacKuen (MacKuen et al., 2010). His work investigates how feelings of anger and anxiety in response to a challenge to one's political policy preferences affect one's subsequent actions and attitudes. To explore this question, MacKuen's team developed a web-based environment that presented subjects with a (fake) news story about a school's decision to change its affirmative action policy. The story was designed to either affirm or challenge the policy preferences subjects had reported on a pretest questionnaire. The web-based environment also provided subjects with the opportunity to explore, if they wished, additional information that would affirm, challenge, or be neutral with regard to the news story they had read. ${ }^{21}$

\footnotetext{
${ }^{21}$ MacKuen and colleagues talk generally about "anxiety," not "practical anxiety" (that is a term I have coined). But as the discussion in the text indicates, and as is readily apparent in their own presentation, they are picking out something very much like it—a variety of anxiety focused on what to do in a novel/difficult situation. Of particular note for our purposes here is the fact that there was little in the experimental design to make subjects think they were being observed or evaluated, and so little to suggest they were experiencing social rather than practical anxiety.
} 
In the present context, the MacKuen experimental design is significant for three reasons. First, their strategy of challenging their subjects' stances on affirmative action policy fits nicely with our focus on difficult moral and practical decisions. After all, affirmative action is a policy that is supported-and challenged - by independently plausible norms: equity norms say one should support affirmative action efforts, while meritocratic norms tell one not to. Thus, the situation they focus on-a situation that raises questions about whether one should continue to support (oppose) affirmative action-is a situation that is likely to introduce the type of uncertainty about what to do that prompts practical anxiety. Second, by creating an environment that can induce distinct emotions (anger or anxiety) and that provides subjects with the opportunity to explore additional information sources, their experimental design provides a rather direct test of the claim that practical anxiety engages accuracy-oriented epistemic behaviors that help one work through uncertainty about what to do. Their results indicate that it does. Subjects for whom the fake news story provoked anxiety sought out more information about affirmative action policy, were more interested in learning more about both sides of the issue, and were more willing to explore new solutions. By contrast, those who experienced anger were less interested in informing themselves, and when they did seek out more information, they tended to just look at things that were in line with their initial views about affirmative action policy. In short, these emotions 'have a direct influence over both attention and open-mindedness'-anxiety brings increases, anger does not (p. 455). Finally, the different patterns of behavior we find between the anxious and the angry subjects suggest that these emotions engage different underlying motivations. The open-minded inquiry we see in the anxious individuals points to an accuracy motivation - a desire to get it right. The more biased search of the angry subjects, by contrast, suggests a more defensive orientation. ${ }^{22}$

The upshot, then, is that practical anxiety is a genuine and important feature of our psychology: it functions as an alarm that helps us recognize situations where we face a particularly novel or difficult choice, and prompts deliberation, information gathering, reassessment, and the like that help us better understand and navigate the situation at hand. ${ }^{23}$

\footnotetext{
${ }^{22}$ For similar results regarding practical anxiety's role in initiating open-minded inquiry in the face of a novel/difficult choice, see Valentino et al. (2008) and Brader (2006).

${ }^{23}$ Though the discussion in the text has focused on the affinities that practical anxiety has with epistemic/metacognitive feelings, it is also likely to have affinities with two other phenomena. First consider the discussion of epistemic vigilance in Sperber et al. (2010). "Epistemic vigilance" refers to a set of capacities that are like practical anxiety in the sense that both are metacognitive tools that regulate reasoning and decision making. But the role that epistemic vigilance plays appears narrower insofar as it is posited as a set of tools that helps individuals protect themselves from misinformation from others; practical anxiety, by contrast, concern decision making uncertainty more generally.

Second, we can consider recent discussions of action selection fluency and disfluency (e.g., Chambon, Sidarus, \& Haggard, 2014; Haggard \& Chambon, 2012). Here the connection with practical anxiety is less clear. Selection (dis)fluency, in brief, is the feeling of agency/control (or its absence) that is associated with the selection of a course of action. Fluent feelings are thought to be the upshot of a lack of conflict in one's assessment of one's choice-options and so prospective evidence that one is making a "good" decision about what to do. Feelings of disfluency, by contrast, are thought to result from conflict in one's assessment of the choice-options and so evidence of a need for greater caution and attention with regard to one's decision making. Though work on selection disfluency has, so far, emphasized its role as a detector of trouble, advocates suggest feelings of disfluency may also function to prompt more strategic and controlled forms of mental processing (Haggard \& Chambon, 2012, p. 392). So understood, feelings of disfluency are likely to play an important role in the development and manifestation of expertise: these feelings are signals about problems with an action or choice that can help one make real-time adjustments (we will return to this idea in $\$ 6.2$ ).

With this overview in hand, we can make three observations about the relationship between practical anxiety and action selection disfluency. (1) At a functional level, there are significant affinities between the two: both operate as alarms that, when triggered, increase attention and prompt risk minimization/assessment efforts. (2) Moving beyond these functional similarities, neuroscientific research indicates that the two mechanisms engage different neural structures: (practical) anxiety is associated with activation of the bed nucleus of the stria terminalis (e.g., Avery, Clauss, \& Blackford, 2016; Kurth, 2018b, chaps. 2-3), while selection disfluency is associated with angular gyrus activation (e.g., Chambon et al., 2014). (3) Combining this pair of observations suggests two (potentially compatible) accounts of the connection between practical anxiety and selection disfluency. First, selection disfluency might be one of several inputs into practical anxiety: feelings of disfluency above a certain level of intensity indicate that an uncertainty threshold has been met, thus engaging practical anxiety and the epistemic behaviors it provokes. Second, practical anxiety and selection disfluency
} 


\section{6 | VINDICATING DELIBERATION}

\section{1 | Responding to the skeptic}

Recall the two-fold challenge facing the proponent of deliberation: demonstrate that there is an essential place for deliberation in our account of virtue, and do so while accommodating the empirical data underlying skepticism about the possibility of genuine practical deliberation. The response, in brief, is this. Deliberation is essential to our ability to choose (and so behave) virtuously in the face of difficult and novel situations. However, we can engage in such deliberation only because of emotions like practical anxiety-emotions that both automatically signal that we face a difficult or novel choice, and engage the genuine, open-minded deliberation that helps bring good practical judgment.

Let us start with why deliberation is essential. As the above cases reveal, deliberation is crucial when we face novel or difficult practical decisions. There are two reasons for this. First, in the face of a hard/novel choice-Should I give more to those in need? What ought I do about my Alzheimer's-stricken mother? - we lack the knowledge and experience necessary to be guided by automatic processes. Hence, the need to think and gather information about how to proceed. Second, hard/novel cases involve both increased uncertainty and a greater possibility for error. So they are situations where, as we have seen, we demand the cautious, well-informed (re)evaluation that comes with careful deliberation $(\$ 4)$.

Bringing this into the context of Annas's proposal, we see that while she is correct that deliberation can help us develop more efficiently as agents, its real value lies in helping us figure out what to do when we face a difficult or new situation. ${ }^{24}$ Moreover, given that the situations where deliberation is needed are ones involving both uncertainty about what to do and a demand for caution, we should expect practical anxiety to be part of the explanation for how this deliberation is engagedpractical anxiety, after all, is an emotion that is in the business of engaging (accuracy-oriented) deliberation in the face of novel and difficult decisions (\$5).

With this in mind, we can turn to the second chore: explaining how deliberation is engaged that both (i) fits with the skeptic's observation that practical judgment starts from and is (largely) driven by automatic processes, and (ii) explains why the resulting reason-giving behavior should be understood as genuine, open-minded deliberation and not a motivated, post hoc rationalization of a decision one has already made.

Consider task (i). When confronted with the doctor's recommendation to put your mother in a care facility, you started to deliberate. Moreover, you did so because of your anxiety. Given the above account of practical anxiety's signaling function (\$5), we can now see both why this is and how it allows us to respond to the skeptic. Practical anxiety is an emotion-an automatic mechanism - that both helps us recognize that we face a difficult decision, and that kicks us into conscious deliberation to help us figure out what to do. It is a Type 1 mechanism that detects novel/ difficult situations and engages Type 2 processes to address what Type 1 mechanisms alone cannot accomplish. Thus, we can agree with the skeptic that practical decision making is grounded in, and driven by, automatic processes while nonetheless insisting there is an essential place for genuine

might represent distinct (but partially overlapping) uncertainty detection mechanisms: practical anxiety principally tracks and responds to uncertainty about potential (physical, social) threats; selection disfluency is more oriented toward uncertainty regarding motor behavior and physical action.

${ }^{24}$ Other advocates of skill-based accounts of virtue have come to a similar conclusion (e.g., Dreyfus \& Dreyfus, 2004). But as we will see (§7), these proposals remain vulnerable to Haidt/Doris-style skepticism. 
deliberation-helping us work through difficult choices when automatic mechanisms alone are not enough. $^{25}$

Turning to task (ii), does practical anxiety bring genuine deliberation? The above cases suggest it does: your anxiety about both whether you were giving too much and what you should do for your mother brought genuine epistemic behaviors that were aimed at helping you work through those decisions. But one might be skeptical. After all, as intuitive as these cases are, they can only do so much to establish that the reason-giving behavior practical anxiety tends to bring represents genuine deliberation and not post hoc rationalization. To address this, we can return to the MacKuen research. As we saw, individuals who were made anxious by the challenge to their affirmative action beliefs were both more interested in learning more about both sides of the issue and more willing to consider alternative proposals. Open-minded inquiry of this sort suggests these individuals were engaged in a genuine effort to think through the challenge to their beliefs about affirmative action, and not a motivated search for evidence that would help support their pre-existing views. That later kind of behavior seems a better description of the individuals who became angry in response to the challenge - not only were they less willing to explore new solutions, but they also tended to only seek out information in line with their antecedent beliefs.

By bringing additional empirical support to our account of practical anxiety as a psychological mechanism that kicks us in to genuine deliberation, the MacKuen results help undermine skepticism about whether we ever engage in substantive deliberation. But we can do better. To see this, recall the differences in motivational orientation that we observed between social and practical anxiety (\$5). Unlike the ego-defensive motivations associated with social anxiety, practical anxiety-as a response provoked in the face of a novel/difficult decision - tends to bring a concern for accuracy. As such, it (in contrast with social anxiety) is more likely to generate substantive, open-minded inquiry rather than motivated, post hoc rationalizations. Recognizing this helps explain both when purported instances of anxiety-provoked deliberation are likely to bring genuine reasoning, and why this is. Deliberation provoked by practical anxiety will tend to be genuine because it is a metacognitive mechanism that is driven by accuracy motivations. By contrast, "deliberation" provoked by social anxiety will more often take the form of self-serving rationalizations because it is a mechanism that is shaped by ego-defensive concerns. So while the skeptic may be right that we confabulate and engage in motivated, post hoc "deliberation," he is wrong to think we cannot explain when and why our reason-giving behavior is likely to be genuine. With this, the two-fold challenge facing the deliberationist has been answered. Deliberation matters for hard choices, and we can engage in it because of emotions like practical anxiety. ${ }^{26}$

\footnotetext{
${ }^{25}$ Objection: The argument in the text presumes anxiety manifests in a particular way: an automatic (pre-conscious) appraisal signals a difficult choice which then brings conscious deliberation. But reflection on anxious experience suggests a different picture: conscious ruminations and worries lead one to realize that one faces a difficult choice which then prompts additional conscious rumination and deliberation. But given that an adequate reply to the skeptic requires we have an automatic mechanism that prompts deliberation, we have a problem: the conscious deliberation and reflection that anxiety brings is the upshot not of some automatic mechanism, but rather conscious deliberation.Reply: While anxiety can come about through this alternative route, there is no reason to think this is the only—or even the typical—way individuals become practically anxious. First, as we have seen ( 5 ), empirical work on the appraisal processes that prompt anxiety indicates that anxious episodes are typically the upshot of automatic, preconscious mechanisms. Second, empirical work also suggests that in cases where reflection brings anxiety, this alternative causal route is the upshot of specific (but atypical) triggers. For instance, clinical levels of self-monitoring appear to engage feedback mechanisms that lead to anxiety-provoking levels of reflection (Barlow, 2001; Mor \& Winquist, 2002).

${ }^{26}$ Seeing that practical anxiety - and the deliberation it generates—is undergirded by accuracy motivations may have implications beyond defending the deliberationist from Doris/Haidt-style skepticism. Though I cannot address the issue here, recognizing the accuracy-oriented nature of practical anxiety suggests that Hugo Mercer and Dan Sperber's claim that the aim of reasoning is not (the preservation of ) truth, but rather winning arguments (Mercer \& Sperber, 2011) is too strong. While their claim may be true for reasoning generated in some-perhaps many-contexts, the discussion here suggests it is mistaken as a claim about deliberation generated by practical anxiety.
} 


\section{2 | An objection}

One might worry that the above conclusion is too hasty. After all, implicit in our defense of deliberation is the assumption that practical anxiety can contribute to the good decision making characteristic of virtuous agency. This claim may seem suspect. The anxious person is someone consumed, even paralyzed, by intense anxiety. And given that anxiety is so unpleasant, one will do just about anything to make it go away. If that is right, one might reasonably think anxiety-provoked deliberation is likely to do more harm than good.

My response is two-fold. First, I suspect that what drives the thought that practical anxiety is unhelpful comes from conflating it with related phenomena like social anxiety. As we have seen, social anxiety brings an ego-defensive motivational orientation. So it is more likely to prompt reasoning that is motivated by self-interested concerns (e.g., a biased search for reasons aimed at presenting oneself in a favorable light). By contrast, practical anxiety brings a concern for accuracy and so typically engages the open-minded deliberation that helps protect against motivated reasoning and other cognitive biases. Once we recognize that anxiety-provoked reasoning can be shaped by these different motivations, the thought that practical anxiety will make us particularly susceptible to pernicious forms of motivated reasoning fades. In fact, it is likely to engage the kind of constructive reasoning we want. Notice as well that practical anxiety-as a sensitivity to uncertainty about what to do in a novel or difficult situation-should be an emotion that we will tend to experience less frequently as we gain experience and so become more competent (virtuous) as agents. But, crucially, the need for practical anxiety will remain even for the most virtuous among us: as we have seen (§4), for any level of human development, there will be times where we face new or hard choice-so there will be times where we need the sensitivity to uncertainty and open-minded deliberation that practical anxiety brings.

Second, and more significantly, practical anxiety is a psychological capacity we can learn to use more effectively. In this regard, it is no different than anger or fear-the value of these emotions is enhanced as we learn to experience them at the right times and in the right ways. In the context of practical anxiety, effective emotional regulation will involve learning to recognize when our unease is the result of uncertainty about what the correct thing to do is (as opposed to uncertainty about, say, whether we will be evaluated or embarrassed). This "cultivating" of practical anxiety will also involve developing trust in the practical anxiety we feel and the open-minded deliberation it brings.

Clearly, more needs to be done to flesh this out. While I cannot do that here, three points are worth noting. First, providing an account of emotion regulation is essential to any account of virtuous agency - so in noting that we need to do this with regard to practical anxiety, we are not adding anything new. But, second, the discussion here provides us with an initial understanding of what cultivating anxiety is likely to involve. Consider, for instance, the research on feelings of disfluency we discussed above in the context of anxiety as a mechanism of metacognition (\$5.2). This work suggests that learning to use practical anxiety more effectively (and so developing competency as an agent) will involve becoming more attuned to, and trusting of, its signals-more sensitive to when deliberation is needed and when we can be comfortable that we are making a good decision. Here the role that feelings of (dis)fluency play in the development of sophisticated motor control and skills (e.g., Murphy \& White, 1978) offers an instructive model for thinking about how practical anxiety (and our affective capacities more generally) can be tuned, and so become trusted, through use (e.g., Railton, 2009; Railton, 2014). However, and this is the third point, (dis)fluency-driven regulation and learning is unlikely to be the whole story-for crucial to these models is the assumption that one gets regular and timely feedback with regard to one's performance (e.g., Chambon et al., 2014, pp. 1-5; Railton, 2009, pp. 108-109). While that is quite plausible for motor skills, it is less 
plausible regarding moral and practical decision making since here feedback is often less timely and regimented. This means there is likely to be a need for learning mechanisms/techniques that can fill the (feedback) gap. On this front, Annas's skill model offers one plausible strategy. Her emphasis on instruction via examples that point to the underlying reasons for acting in a particular way suggests one way we could augment our understanding of when practical anxiety is (in)appropriate: the examples and accompanying reasons would, in a sense, serve as a proxy for more direct forms of input-thus narrowing the feedback gap (Kurth, 2018a, 2018b, chap. 6). ${ }^{27}$

Taken together, these observations not only undermine the thought that when it comes to our development as virtuous agents anxiety-provoked deliberation is bound to do more harm than good, but they also help us understand how we can learn to trust, and so make better use of, our practical anxiety.

\section{7 | CONCLUSION: TOWARD A BETTER SKILL-BASED ACCOUNT}

We have our response to the skeptic's challenge: deliberation is essential because automatic mechanisms alone are not enough to help us work through novel and difficult decisions. That said, practical decision making is still very much grounded in, and driven by, automatic processes: routine decisions often do not require conscious deliberation; and when deliberation is needed, it is engaged via automatic mechanisms like practical anxiety. Moreover, we need not deny that much of our reason-giving behavior is confabulatory. But we can insist that whether it is will turn on our underlying motivations - is it driven by a desire for accuracy or something else?

It is also worth emphasizing that in acknowledging the significance of practical anxiety, we do not need to deny that Annas's skill model captures important features of virtue and its development: learning is more efficient when it comes via examples and a drive to aspire; virtuous thought and action can (often) be fluid, harmonious, and free of psychological conflict. The problem lies in thinking that her version of the skill model captures all that matters. We have seen that it does not. Emotions - both ones that are pleasant to experience and ones that are not-matter for our ability to (learn to) be virtuous. We are virtuous, at times, because of the psychological conflict and anxiety we experience.

Recognizing this suggests that if we are interested in a skill-based account of virtuous agency, we are likely to do better if we move away from the two assumptions that bring trouble to Annas's proposal: (i) skills and virtue acquisition must be the product of explicit instruction that gives one the ability to explain why one did what they did, and (ii) once skills and virtue have been acquired, all subsequent action is fluid, harmonious, and deliberation-free. In this regard, the skill-based accounts we find in recent work from Peter Railton (2009), David Velleman (2008), and Herbert and Stuart Dreyfus (1991) look quite promising. These proposals rely on less intellectualized accounts of skill/virtue acquisition and they acknowledge that virtuous action can require deliberation and reflection. ${ }^{28}$

\footnotetext{
${ }^{27}$ For an alternative, more Kantian proposal, see Barbara Herman's discussion of the role that moral knowledge via "rules of moral salience" play in one's development as a virtuous agent (1993, especially chap. 4). I say more about Herman's proposal in the context of anxiety in Kurth (2018a, 2018b, chap. 5).

${ }^{28}$ Brownstein (2014) argues that, like Annas, Railton and Velleman are committed to skilled/virtuous agents always being able to articulate their reasons for acting one way rather than another, and so are just as vulnerable to the charge of over-intellectualization. But Brownstein's argument relies on an uncharitable reading of the Railton and Velleman's proposals. They qualify their claims about the extent to which agents will be able to explain their actions in a way that Annas does not, and so are not susceptible to Brownstein's charge of over-intellectualization.
} 
However, while these proposals may certainly avoid some of the problems that undermined Annas's version of the skill model, they also lack the resources to answer the skeptic. The problem, in short, is that while Railton, Velleman, and the Dreyfuses acknowledge the need for genuine deliberation, they say almost nothing about how it is engaged. For instance, Railton identifies 'the ability to detect, without reflecting and deliberating, conditions calling for reflection and deliberation' as a competency that we must have if we are to exhibit the reasons responsiveness that is characteristic of human agency (Railton, 2009, p. 108). Similarly, Velleman maintains that much of human agency is automatic in the sense of being free of conscious self-regulation. Yet he also holds that our 'capacity for [conscious] self-regulation remains in reserve in case it is needed' (2008, p. 188). For their part, the Dreyfuses note that 'an expert facing a novel situation..., like a beginner, must resort to [deliberation via] abstract principles' (1991, p. 241). But in all three cases, we get little beyond the providing of examples where it seems intuitively plausible that mechanisms of conscious deliberation/reflection have been engaged.

But merely pointing to such examples is not enough. Because these examples provide no details about the underlying psychological mechanisms - much less how they are engaged — what we get is less an answer to our question than an illustration of what needs to be explained in the first place. Thus, these proposals provide little that could be used in response to a skeptic who maintains that these examples are not really examples of conscious deliberation, but rather just instances of confabulation and post hoc rationalization.

Notice, however, that these difficulties go away if we incorporate a role for practical anxiety into the moral psychology of these proposals. After all, it is an automatic mechanism that is in the business of engaging conscious deliberation and reflection when automatic processes alone prove insufficient. So it is something Railton, Velleman, and the Dreyfuses can point to explain-in a manner much like what we just did in $\$ 6$ - how genuine, nonconfabulatory deliberation can be engaged. The upshot, then, is that if you are interested in a skill-based account of virtuous agency that can silence the skeptic, you should build from a psychology that takes seriously the work that practical anxiety can do.

\section{ACKNOWLEDGEMENTS}

Versions of this paper were presented at Georgetown University, the University of Colorado, the University of St. Andrews, and Washington University in St. Louis - thanks to those audiences for helpful discussions. I have also benefited from conversations with Mark Berger, David Brink, Michael Brownstein, Carl Craver, Justin D'Arms, John Doris, Dan Jacobson, Anne Jeffrey, David Shoemaker, and Kit Wellman.

\section{REFERENCES}

Annas, J. (2008). The phenomenology of virtue. Phenomenology and Cognitive Science, 7, 21-34.

Annas, J. (2011). Intelligent virtue. Oxford: Oxford University Press.

Arango-Muñoz, S. (2010). Two levels of metacognition. Philosophia, 39, 71-82.

Arpaly, N. \& Schroeder, T. (2014). In praise of desire. Oxford: Oxford University Press.

Avery, S., Clauss, J. \& Blackford, J. (2016). The human BNST. Neuropsychopharmacology, 41, 126-141.

Barlow, D. (2001). Anxiety and its disorders (2nd ed.). New York: Guilford Press.

Bloomfield, P. (2000). Virtue epistemology and the epistemology of virtue. Philosophy and Phenomenological Research, 60, $23-43$.

Brader, T. (2006). Campaigning for hearts and minds. Chicago: University of Chicago Press.

Brink, D. \& Nelkin, D. (2013). Fairness and the architecture of responsibility. In D. Shoemaker (Ed.), Oxford studies in agency and responsibility (Vol. 1, pp. 284-313). Oxford: Oxford University Press.

Brownstein, M. (2014). Rationalizing flow. Philosophical Studies, 168, 545-568. 
Chambon, V., Sidarus, N. \& Haggard, P. (2014). From action intentions to action effects: How does the sense of agency come about? Frontiers in Human Neuroscience, 8, 1-9.

Christensen, W., Bicknell, K., McIlwain, D. \& Sutton, J. (2015). The sense of agency and its role in strategic control for expert mountain bikers. Psychology of Consciousness: Theory, Research, and Practice, 2(3), 340-353.

Corr, P. (2008). The reinforcement sensitivity theory of personality. In P. Corr \& N. McNaughton (Eds.), The reinforcement sensitivity theory of personality (pp. 428-507). New York: Cambridge University Press.

Csikszentmihalyi, M. (1991). Flow: The psychology of optimal experience. New York: Harper.

Davis, M., Walker, D. L., Miles, L. \& Grillon, C. (2010). Phasic vs sustained fear in rats and humans: Role of the extended amygdala in fear vs anxiety. Neuropsychopharmacology, 35(1), 105-135.

Doris, J. (2015). Talking to ourselves. Oxford: Oxford University Press.

Dreyfus, H. L. \& Dreyfus, S. E. (1991). Towards a phenomenology of ethical expertise. Human Studies, 14(4), 229-250.

Endler, N. \& Kocovski, N. (2001). State and trait anxiety revisited. Anxiety Disorders, 15, 231-245.

Enoch, D. (2006). Agency, shmagency. Philosophical Review, 115, 169-198.

Foot, P. (1978). Virtues and vices. In P. Foot (Ed.), Virtues and vices (pp. 1-18). Berkeley: University of California Press.

Frankfurt, H. (1971). Freedom of the will and the concept of a person. Journal of Philosophy, 68, 5-20.

Gray, J. \& McNaughton, N. (2000). The neuropsychology of anxiety. Oxford: Oxford University Press.

Haggard, P. \& Chambon, V. (2012). Sense of agency. Current Biology, 22, 390-392.

Haidt, J. (2001). The emotional dog and its rational tail. Psychological Review, 108, 814-834.

Herman, B. (1993). The practice of moral judgment. Cambridge, MA: Harvard University Press.

Hookway, C. (1998). Doubt: Affective states and the regulation of inquiry. Canadian Journal of Philosophy, 24(Suppl), $246-264$.

Jacobson, D. (2012). Moral dumbfounding and moral stupefaction. In M. Timmons (Ed.), Oxford studies in normative ethics (Vol. 2, pp. 289-316). Oxford: Oxford University Press.

Kennett, J. \& Fine, C. (2009). Will the real moral judgment please stand up? Ethical Theory and Moral Practice, 12, 77-96.

Klein, G. (1999). Sources of power. Cambridge, MA: MIT Press.

Korsgaard, C. (2009). Self-constitution. Oxford: Oxford University Press.

Kurth, C. (2015). Moral anxiety and moral agency. In M. Timmons (Ed.), Oxford studies in normative ethics (Vol. 5, pp. 171-195). Oxford: Oxford University Press.

Kurth, C. (2016). Anxiety, normative uncertainty, and social regulation. Biology \& Philosophy, 31, 1-21.

Kurth, C. (2018a). Anxiety: A case study in the value of negative emotions. In C. Tappolet, F. Teroni \& A. Konzelmann (Eds.), Shadows of the soul: Philosophical perspectives on negative emotions (pp. 95-104). New York: Routledge.

Kurth, C. (2018b). The anxious mind. Cambridge, MA: MIT Press.

Leary, M. \& Kowalski, L. (1995). Social anxiety. New York: Guilford Press.

Levenson, R. (1999). The intrapersonal function of emotion. Cognition and Emotion, 13, 481-504.

Lewis, M. (2005). Bridging emotion theory and neurobiology through dynamic systems modeling. Behavioral and Brain Sciences, 28, 169-245.

MacKuen, M., Wolak, J., Keele, L. \& Marcus, G. E. (2010). Civic engagements: Resolute partisanship or reflective deliberation. American Journal of Political Science, 54(2), 440-458.

Marks, I. \& Nesse, R. (1994). Fear and fitness: An evolutionary analysis of anxiety disorders. Ethology and Sociobiology, 15, $247-261$.

Mathews, A. (1990). Why worry? The cognitive function of anxiety. Behaviour Research \& Therapy, 28, 455-468.

McDowell, J. (1998). Mind, value and reality. Cambridge, MA: Harvard University Press.

Mercer, H. \& Sperber, D. (2011). Why do humans reason? Behavioral and Brain Sciences, 34, 57-111.

Mor, N. \& Winquist, J. (2002). Self-focused attention and negative affect: A meta-analysis. Psychological Bulletin, 128, 638-662.

Murphy, M. \& White, R. (1978). In the zone. New York: Penguin.

Nagel, J. (2010). Epistemic anxiety and adaptive invarientism. Philosophical Perspectives, 24, 407-435.

Öhman, A. (2008). Fear and anxiety. In M. Lewis, J. M. Haviland-Jones \& L. F. Barrett (Eds.), Handbook of emotions (pp. 709-729). New York: Gilford Press.

Oppenheimer, D. (2008). The secret life of fluency. Trends in Cognitive Science, 12, 237-241.

Perkins, A. \& Corr, P. (2006). Reactions to threat and personality. Behavioral Brain Research, 169, 21-28.

Pizarro, D. \& Bloom, P. (2003). The intelligence of moral intuitions. Psychological Review, 110, 193-196.

Price, M. \& Norman, E. (2008). Intuitive decisions on the fringes of consciousness. Judgment and Decision making, 3, $28-41$.

Proust, J. (2009). Is there a sense of agency of thought? In L. O'Brien \& M. Soteriou (Eds.), Mental actions and agency (pp. 253-275). Oxford: Oxford University Press.

Railton, P. (2009). Practical competence and fluent agency. In D. Sobel \& S. Wall (Eds.), Reasons for action (pp. 81-115). Cambridge: Cambridge University Press.

Railton, P. (2014). The affective dog and its rational tale. Ethics, 124, 813-859.

Rawls, J. (1971). Theory of justice. Cambridge, MA: Harvard University Press.

Sauer, H. (2011). Social intuitionism and the psychology of moral reasoning. Philosophy Compass, 6, 708-721.

Slote, M. (2014). A sentimentalist theory of mind. Oxford: Oxford University Press.

Sperber, D., Clement, F., Heintz, C., Mascaro, O., Mercer, H., Origgi, G. \& Wilson, D. (2010). Epistemic vigilance. Mind \& Language, 25(4), 359-393. 
Stanley, J. (2011). Know how. Oxford: Oxford University Press.

Stichter, M. (2015). Practical skills and practical wisdom in virtue. Australasian Journal of Philosophy, 94, 435-448.

Stohr, K. (2003). Moral cacophony: When continence is a virtue. The Journal of Ethics, 7, 339-363.

Sutton, J. (2007). Batting, habit and memory. Sport in Society, 10(5), 763-786.

Thompson, V. (2009). Dual-process theories: A metacognitive perspective. In J. Evans \& K. Frankish (Eds.), In two minds: Dual processes and beyond (pp. 171-195). Oxford: Oxford University Press.

Tiberius, V. (2013). In defense of reflection. Philosophical Issues, 23, 223-243.

Valentino, N., Hutchings, V., Banks, A. \& Davis, A. (2008). Is a worried citizen a good citizen? Political Psychology, 29, $247-273$.

Velleman, D. (2008). The way of the wanton. In C. Mackenzie \& K. Atkins (Eds.), Practical identity and narrative agency. New York: Routledge.

Watson, G. (1982). Free agency. In G. Watson (Ed.), Free will (pp. 337-351). Oxford: Oxford University Press.

Wolf, S. (1990). Freedom within reason. Oxford: Oxford University Press.

How to cite this article: Kurth C. Emotion, deliberation, and the skill model of virtuous agency. Mind Lang. 2018;1-19. https://doi.org/10.1111/mila.12186 